\title{
JUAN CARLOS ONETTI
}

(1909-1994)

POR

\author{
Hugo J. VeranI \\ University of California, Davis
}

El 30 de mayo pasado murió en Madrid Juan Carlos Onetti Borges de un paro cardíaco, tras una larga enfermedad hepática. Había nacido en Montevideo el $1^{\circ}$ de julio de 1909. Sus restos mortales fueron incinerados en el cementerio de la Almudena, sin ceremonias, epitafios ni flores, con la sencillez y austeridad como vivió sus 84 años.

En una entrevista de 1969 comentó Onetti, con su habitual ironía: "Siempre dije que los críticos son la muerte; a veces demoran, pero siempre llegan". Fue una de las cumbres de la narrativa en lengua española de este siglo, pero el reconocimiento de su maestría le llegó muy tarde. Hasta mediados de los sesenta era leído por un grupo íntimo de iniciados y no tenía adeptos fuera del ámbito uruguayo, a pesar de haber vivido unos veinte años en Buenos Aires (1930-1934 y 1941-1955), donde publicó la mayoría de sus obras casi sin repercusión crítica. Su narrativa comienza a trascender las fronteras rioplatenses con ediciones venezolanas de fines de los sesenta y, especialmente, con la publicación mexicana de sus Obras completas en 1970, que le abren las puertas del mundo hispano. Al ser distinguido en 1980 con el Premio Miguel de Cervantes adquiere el renombre internacional que ya se merecía desde El pozo (1939) y, sobre todo, desde La vida breve (1950), una admirable lección del arte de narrar. Carente de ambición de éxito, obtuvo la celebridad de manera accidental, sin haber buscado de modo deliberado ninguna recompensa. Como si escribiera de sí mismo, dijo una vez de William Faulkner, su maestro: "Obtenía en la noche y la soledad, sólo para sí mismo, sus triunfos y fracasos. Sabía que lo que llamamos éxito no pasa de una vanidad amañada: amigos, críticos, editores, modas" (1962). Incluso su muerte fue tardía, si se tiene en cuenta que su vida fue una sostenida e implacable forma de autodestrucción, equiparable a un largo suicidio. Agobiado por frecuentes crisis depresivas, dedicado a la bohemia noctámbula, con un organismo intoxicado por el alcohol, el tabaco y los barbitúricos, que deberían haber precipitado su muerte, despistó al calendario y sobrevivió contra todo pronóstico, anclado en la cama pero con una asombrosa lucidez. Como cuenta Mario Benedetti, su gran amigo del exilio madrileño: "En los últimos años, uno estaba tan habituado a que Onetti casi moría y luego resucitaba y hasta escribía una novela nueva, que a todos (incluida Dolly, su mujer) nos costó admitir que esta vez no había resurrección".

Conocí a Onetti un anochecer frío y lluvioso en julio de 1970, en su modesto apartamento de dos ambientes en un sexto piso en la calle Gonzalo Ramírez, de cara al Río 
de la Plata, en el Barrio Sur montevideano. Hacía seis meses que trataba de conocerlo personalmente. Una admiradora suya me había servido de pasaporte cuando temía ya no tener la oportunidad de tratar a un hombre notorio por rehuir el contacto con la gente. Era Director de Bibliotecas Municipales de Montevideo pero nunca estaba en su despacho. Su cuarta y definitiva esposa, la violinista Dorotea Muhr (Dolly) - la cara de la bondad y no el "ignorado perro de la dicha", como la llamara en la dedicatoria de La cara de la desgracia - estaba en Buenos Aires, ausencia que le permitía desconectar el timbre y permanecer a salvo de intromisiones, aislarse aún más y pasar el tiempo echado, leyendo o imaginándose desoladas historias sanmarianas. En ese entonces no tenía teléfono. Se empeñaba en mantenerse al margen de la vida pública y sus pormenores, desinteresado de su destino profesional.

Me recibió con un traje negro y una corbata también negra, como cumpliendo con el deber de adaptarse a su imagen sombría, incómodo no tanto por su vestimenta como por la presencia de un intruso que presagiaba un interrogatorio. Como no sabía por donde empezar, mencioné la dificultad que había tenido para que accediera a verme y fiel a su modo de ser me respondió, desde el fondo de su tolerante hastío: "Es que la gente no se da cuenta que uno es un solitario". Cruzamos unas pocas palabras sin romper el hielo, por timidez, desgano o indiferencia, cuando tras un largo y penoso silencio me preguntó repentina e imprevistamente, con una voz grave que arrastraba con lentitud: "¿A usted le molesta si yo me acuesto?". Balbuceando no sé qué lo seguí —pues ya se había ido sin esperar respuesta- a una habitación con olor a humedad y a tabaco rancio. Echado en la cama, semiincorporado y con un vaso de vino tinto en la mano estaba más animado y fingía interesarse en la conversación, hasta que vio el cuestionario que con tonta solemnidad saqué de un portafolio y pasó de oir en silencio o asentir con la cabeza o con monosílabos a murmurar con fastidio un "no me joda", pues rechazaba el diálogo ordenado y sólo conversaba si le importaba el tema, y comentar su propia obra no era tal cosa. Había que cambiar de rumbo si quería traspasar la máscara huraña y despectiva con que creaba un distanciamiento, un aire de impenetrabilidad que protegía una intimidad no exenta de ternura. De la ventana de su dormitorio se veía la ciudad junto al río y un edificio fantasmal y en ruinas, que no era más que unas chapas herrumbradas - "el astillero", insinuó con indolencia socarrona y una gran risa secreta. Cerca de la cama había una enorme cabeza de Buda, con una enigmática sonrisa, que parecía estar por encima de todo; muy pocos libros en una estantería, pero muchos más esparcidos por el suelo y amontonados debajo de la cama, casi todos policiales. Sobre la cabecera de la cama tenía una foto de Faulkner, clavada en la pared. Por fortuna se me ocurrió mencionar que mis estudios universitarios me habían llevado al sur norteamericano y se le iluminó la mirada. Se arrodilló en la cama y se persignó frente a la foto, con una mueca burlona, mezcla de reverencia y de ironía, una gran tomadura de pelo a un estudiante con pretensiones intelectuales. Llevado a su terreno, el diálogo surgía espontáneamente, en simple plan de amistad, con un resignado entusiasmo y un corrosivo sentido del humor. A medida que transcurría, la conversación se hacía más personal. Hablaba sin énfasis y sin protagonismo de sus largos períodos de insomnio y de su cansancio crónico, de la desesperanza y del hastío que padecía, de la pobreza del medio local ("sin dinero no hay cultura", comentó), de la gratuidad de todo, sin posibilidad de cambio. 
A Onetti le fastidiaba la vida mundana e intelectual, la "literatosis", como solía llamar las actividades de los hombres de letras - congresos, debates, conferencias, entrevistas. (Un solo ejemplo, muy posterior, que presencié: en un homenaje que se le tributó en la Universidad Veracruzana en 1980, el Gobernador del Estado presentó a Onetti al público de manera protocolar y cuando le dio la palabra éste simplemente dijo "yo no hablo" y no habló). En marzo de 1975 coincidimos en el Hotel Cuzco de Madrid, con motivo de celebrarse el XVII Congreso del Instituto Internacional de Literatura Iberoamericana en la capital española. Él estaba allí contra su voluntad, pues no tenía muchas alternativas: había decidido exiliarse como consecuencia de la humillación que le impusieron las autoridades militares al encarcelarlo por tres meses por haber integrado el año anterior un jurado que premió un cuento que la dictadura consideró "pornográfico". Vi a Onetti por última vez en Madrid en 1990, en un octavo piso de la Avenida de América, postrado ya definitivamente por voluntad propia. A su muerte, llevaba más de diez años recluido en su habitación, contemplando el mundo desde la cama, de espaldas a la luz que entraba por el ventanal, viviendo de sus recuerdos y de la imaginación.

Onetti mantuvo siempre una autenticidad invariable, sin concesiones a nadie ni a nada, sin más fe que en su vocación de narrador. Sentía un escepticismo absoluto ante la vida y una "total indiferencia" a todo lo que no fuera escribir. Consideraba "cómicas todas las convicciones" y fue incapaz de integrarse a ninguna causa, de romper el aislamiento y el nihilismo. Esta visión fatalista de la vida humana, la convicción de que no existen alternativas al no sentido de la vida, estaba profundamente arraigada en él. En un artículo de 1940, confiesa que acabó por aburrirse de seguir la Segunda Guerra Mundial y de preocuparse por cumplir con un deber moral que traicionaba su modo de ser: "Mi vida son los libros, una pieza en una casa de pensión, dos o tres amigos viejos [...]. En fin: pido perdón por esto, pero es más fuerte que mi voluntad". Su pacto con la literatura era total y excluyente y muchas veces repitió que "el único compromiso que acepto es la persistencia de escribir bien y mejor" (1962). Escribir fue su felicidad y su condena, una pasión febril e indeclinable que lo obligaba a retornar una y otra vez a su territorio mítico, a soñar despierto las crónicas de desencanto y de fracaso de los habitantes de Santa María. En una temprana nota de Marcha definió el credo del verdadero escritor, cuando éste es algo más que un aficionado: "Escribirá porque sí, porque no tendrá más remedio que hacerlo, porque es su vicio, su pasión y su desgracia" (1939). Y en su "Réquiem por Faulkner" fue aún más contundente: "En primer lugar, [Faulkner] define a lo que entendemos como un artista: un hombre capaz de soportar que la gente - $y$, para la definición - cuanto más próxima mejor, se vaya al infierno, siempre que el olor a carne quemada no le impida continuar realizando su obra. Y un hombre que, en el fondo, en la última profundidad, no dé importancia a su obra" (1962). Bien puede decirse que el ejercicio de la literatura era su única razón para vivir, la única afirmación posible de la vida. El resultado de esta entrega radical a su devoradora vocación de existir escribiendo fue su progresivo aislamiento y enclaustramiento, refugiado en un mundo imaginario definitivamente cerrado sobre sí mismo, que se autorrefiere y autoabastece permanentemente. Como si ya no hubiera separación alguna entre realidad y ficción, él mismo se fue pareciendo cada vez más a sus propios personajes.

Sobre el talento creador de uno de los grandes fundadores de la nueva narrativa latinoamericana existen ya numerosas aproximaciones críticas y muchas más se escribirán. 
Me parece más pertinente terminar esta semblanza sin comentar aquí su trayectoria de escritor, que ya he hecho muchas veces. Prefiero citar el final de Cuando ya no importe (1993), el último fragmento de la larga historia que Onetti venía escribiendo desde hacía sesenta años (su primer relato édito es de 1933), el libro donde salda definitivamente sus cuentas con la literatura y con la vida. El narrador, un nuevo protagonista llamado Juan Carr (¿Juan Carlos?), recapitula lo vivido y lo escrito en una especie de larga despedida o "lento epílogo", síntesis de la caída gradual e irreversible de una existencia desolada, que converge en la certeza del inevitable fin: "Escribí la palabra muerte deseando que no sea más que eso, una palabra dibujada con dedos temblones". En la literatura reside el conjuro contra el olvido; en el último párrafo que escribe se entrecruza el homenaje a la poesía de Paul Valery y su "cementerio marino" con la alusión a la novela de un viejo amigo, Lloverá siempre de Carlos Denis Molina. Onetti cierra su obra y su vida con estas conmovedoras palabras, de intransferible poder evocativo y maestría:

Otra vez, la palabra muerte sin que sea necesario escribirla. Hay en esta ciudad un cementerio marino más hermoso que el poema. Y hay o había o hubo allí, entre verdores y el agua, una tumba en cuya lápida se grabó el apellido de mi familia. Luego, en algún día repugnante del mes de agosto, lluvia, frío y viento, iré a ocuparlo con no sé qué vecinos. La losa no protege totalmente de la lluvia y, además, como ya fue escrito, lloverá siempre. 